\title{
Fiscal Shocks and Fiscal Risk Management
}

\author{
Huw Lloyd Ellis and Xiaodong Zhu \\ Department of Economics \\ University of Toronto \\ 150 St. George Street \\ Toronto, Ontario \\ Canada M5S 3G7
}

July 1998

\begin{abstract}
We use the returns on a set of international financial securities to identify exogenous shocks to the Canadian federal surplus. We find that a large portion of the variation in the surplus can be replicated by a linear combination of these returns and that the rising debt observed in the 1980s and 1990s was a result of adverse exogenous shocks and a delayed response by the government to these shocks. We develop a formal framework to evaluate the potential gains from a fiscal risk management strategy, using these securities to hedge against exogenous shocks. We show that fiscal risk management can generate significant welfare gains by enhancing the sustainability of fiscal policy and thereby lowering average tax rates.
\end{abstract}

Keywords: Fiscal policy, sustainability, asset pricing, risk management.

JEL Classification Numbers: E6, F3, H6

This paper has benefitted from the comments of Angelo Melino and seminar participants at Toronto, Waterloo, York, the 1997 meetings of the Canadian Macroeconomics Study Group and the Society for Economic Dynamics. All remaining errors and omissions are our own. Funding from SSHRCC is gratefully acknowledged.

E-mail address for correspondence: xzhu@ chass.utoronto.ca. 


\section{Introduction}

The large public debts accumulated by many OECD economies during the last two decades have created serious concern about the sustainability of fiscal policies and have become a major topic of policy debate. Much of the economic literature on this subject rationalizes these large public debts as the consequence of public sector bias towards deficits. ${ }^{1}$ However, the analysis fails to explain why the public debt problem emerged in the mid-seventies and not before (see Alesina and Perotti, 1995). To address this question, some authors have started to consider the role of exogenous "fiscal shocks" - unexpected changes in government spending and revenues — as a source of the rising public debt. However, their attention has largely been focused on how political and fiscal institutions affect the government's response to fiscal shocks, ${ }^{2}$ rather than on the shocks themselves. Few studies have tried to investigate the actual contribution of fiscal shocks to the rising public debt. The question of what governments can and should do to mitigate these shocks is also left unanswered.

The focus of this paper is on fiscal shocks and it contributes to the literature in three key ways. First, we estimate the contribution of exogenous factors to variations in the primary surplus and measure their empirical importance to the rising public debt. Second, we characterize the response of fiscal policy to these shocks. Finally, we show how a policy of fiscal risk management can mitigate the adverse consequences of these external influences, and estimate the potential gains from fiscal risk management in terms of improved sustainability, lower average taxes and increased welfare. As an empirical example we focus on the primary surplus and debt levels of the Canadian federal government over the last forty years. Canada provides a good example for our analysis because, during this period, the behavior of the public debt in Canada was very similar to that of the OECD average. Moreover, since Canada is a small open economy, it is much easier to identify fiscal shocks that are clearly exogenous to the Canadian government.

A key novelty of our analysis is that we identify exogenous fiscal shocks using the returns on several international financial securities. The idea behind this approach is that if the financial market is relatively complete, then the relevant risk can be represented by some combination of these market returns. ${ }^{3}$ In addition to being exogenous with respect to Canada's fiscal policy, we find that these variables capture a larger portion of the variation in the primary surplus than the growth rate of GDP or the unemployment rate - variables that have been used in previous studies (e.g. Roubini and Sachs, 1989). Indeed, our empirical analysis reveals that the majority of the variation in the primary surplus over this period can be replicated by a linear combination of returns on international financial securities. In particular, the large deficits that were experienced in the seventies and early

\footnotetext{
1 See Persson and Svensson (1989), Roubini and Sachs (1989), Tabellini and Alesina (1990), Grilli, Masciandaro and Tabellini (1991), Tabellini (1991), Von Hangen (1992) and Alesina and Perotti (1996). Alesina and Perotti (1995) provides an excellent survey of this literature.

2 See Von Hagen (1991), Alt and Lowry (1994), Poterba (1994), Bayoumi and Eichengreen (1995), Bohn and Inman (1995) and Alesina and Perroti (1996).

3 This is referred to in the finance literature as the "spanning property"
} 
eighties can largely be attributed to these exogenous fiscal shocks. We also find that the surplus process is best characterized by a time-invariant function of current and past shocks with an abrupt policy regime shift towards higher primary surplus in the mid-1980s.

Our empirical results suggest that the problem of rising public debt in Canada was caused by a series of adverse exogenous shocks that occurred in the late seventies and early eighties, and that the problem was aggravated by the delay in the government's response to the rising debt. Rather than adjusting the primary surplus continually in response to the rising debt level, the Canadian fiscal authorities maintained the original fiscal policy rule long after the adverse shocks occurred. A significant shift in the stance of fiscal policy took place only when the net debt reached an alarmingly high level and a new government came into power. ${ }^{4}$ Our evidence appears to be more consistent with the predictions of a political economy model (e.g. Alesina and Drazen, 1991) that emphasizes the role of adjustment costs in causing delays, rather than with the basic tax-smoothing model.

The use of financial market returns to represent exogenous shocks to the primary surplus allows us to address two key questions: (1) To what extent can exogenous shocks to the primary surplus be diversified in the international financial market, and (2) What are the potential gains of adopting such a fiscal risk management strategy? According to the optimal dynamic taxation theories of Barro (1979) and Lucas and Stokey (1983), tax rates should be maintained at relatively constant levels and should not be used to offset all of the exogenous shocks to the primary surplus. For political and institutional reasons, fiscal authorities may not be able to adjust fiscal policy instantaneously. In the absence of state contingent borrowing and lending, however, a stable fiscal policy may become unsustainable as the effects of the exogenous shocks accumulate and result in a rising debt, ${ }^{5}$ which could force the government to drastically raise taxes and cut spending in order to reduce the debt. The more volatile is the primary surplus, the more likely it is that the tax rate will have to be increased in the future. By hedging away the volatile component of the primary surplus that is associated with the exogenous shocks, fiscal risk management might help to reduce the probability of an excessively large and rising public debt.

To address these issues, we develop a conceptual framework that is consistent with our empirical observations and consider a simple hedging strategy that effectively replaces the diversifiable component of the primary surplus with a constant cash-flow that has the same present value. We estimate the gains from fiscal risk management in terms of the sustainability of fiscal policy, average tax rates and welfare. We find that by increasing the sustainability of fiscal policy, fiscal risk management results in sizable welfare gains by lowering expected tax rates in the short and long run. However, in order to capture these gains, it is important that the hedging strategy be adopted only when the net debt is at a sufficiently low level. When the level of the net debt is high, hedg-

\footnotetext{
4 1985, the year in which the fiscal policy change took place, is also the year when the Conservative Party became the majority party in Canadian parliament.

5 Bohn (1991) provides several theoretical examples that illustrate the need for the government to issue state contingent bonds in stochastic economies.
} 
ing may have the effect of reducing the probability that the net debt declines, thereby making any given policy less sustainable. We characterize the conditions under which hedging is desirable. Our analysis implies that fiscal risk management should best be viewed as a way of avoiding future debt problems rather than solving current ones.

We are not the first to emphasize the importance and potential benefits of using financial market instruments in government finance. In their seminal work, Lucas and Stokey (1983) show that state contingent bonds are crucial in implementing the optimal fiscal policy and maintaining the timeconsistency of the policy in the face of stochastic shocks. ${ }^{6}$ Bohn (1990) provides empirical evidence that financial market instruments may help the US government to further smooth its tax rates and, therefore, improve welfare. In contrast, we emphasize the role of fiscal shocks in affecting the variation in budget surplus rather than in the tax rates. Our analysis shows that the impacts of these shocks have largely been absorbed by the government through risk-free borrowing and lending and have, therefore, resulted in rising debt. While Bohn argues that risk management may help the government to reduce the short-run variations in the tax rates, we show that fiscal risk management can also help to reduce the probability of having a high debt, enhancing the long-run stability of fiscal policy and thereby raise welfare.

The analysis contained in the rest of the paper is divided into two sections. In Section 2 we estimate the impact of exogenous factors on the surplus process and determine the response of the fiscal policy stance of the government to those factors. In Section 3 we develop a method for evaluating the potential gains of fiscal risk management, and apply it to the Canadian example using the empirical specification developed in Section 2. Section 4 offers some concluding remarks.

\section{Fiscal Shocks and Policy Response}

After being consistently in surplus until the early 1970s, the Canadian budget balance exhibited almost continuous deficits during the seventies and early eighties, followed by persistent surpluses from the mid-1980s. The purpose of this section is to determine how much of the variation in the surplus can be attributed to external influences and what parts to significant shifts in "fiscal stance".

\subsection{The Exogenous Fiscal Shocks}

We use the market returns on a set of international financial assets to measure fiscal shocks. These market returns have been used extensively in the finance literature to represent underlying factors in stock market returns and to capture cyclical activity in the US (and, hence, the Canadian) economy. Since Canada is a small open economy, it is safe to assume that these international variables are not

6 Zhu (1995) shows that, in an economy with capital, government bonds that are linked to capital returns can be used to ensure the time-consistency of optimal fiscal policy even if there are no stochastic shocks. 
influenced by the government's fiscal policy. Moreover, if the financial markets are relatively complete, then it should be possible to replicate a large portion of the fiscal risk using some combination of these returns.

The asset return variables are the value weighted return on the New York Stock Exchanges VWR (from the CRSP tape), the dividend yield DIV on the CRSP value-weighted index (measured as a 1-year backward moving average of dividends divided by the most recent stock price), the 3-month Treasury bill rate TBILL, the 1 year moving average of the 3-month Treasury bill rate TBMA; and the rate of return on 10 year government bonds, LONGR. These variables, or linear combinations of them, have been found to forecast asset returns and are discussed in more detail in Campbell (1996). We multiply each of these by the nominal exchange rate to obtain the Canadian dollar value of the return on each US dollar invested. This ensures that the US dollar values of the returns are independent of the exchange rate and, therefore, Canadian government's policy. Let $X_{t}$ denote the vector that contains these return variables.

\subsection{The Fiscal Policy Rule}

We adopt the following specification of the primary surplus process:

$$
s_{t}=f_{t}+\mathbf{a}^{\prime} X_{t}+\rho s_{t-1}+\varepsilon_{t} .
$$

Here $s_{t}$ is the ratio of the nominal primary surplus to the trend of nominal GNP. The vector a measures the marginal impact of the exogenous shocks to the primary surplus. It represents both the effects of the shocks under a given policy and the effects through policy response to shocks. ${ }^{7}$ The term $f_{t}$ summarizes the permanent components of the government's policy variables. It could be time-varying and may change in response to the debt level and political events. The lagged surplus term is intended to capture the persistency of the surplus process. ${ }^{8}$ Finally, the error term $\varepsilon_{t}$ is assumed to be a normal random variable that is uncorrelated with $X_{t}, f_{t}$ and $s_{t-1}$. In section 3 , we present a small open economy model in which the equilibrium primary surplus process takes exactly the form that is specified in (1) with $\rho=0$, and $f_{t}$ is a function of the effective tax rate on output.

In order to estimate (1), we need to specify how the policy variable $f_{t}$ evolves over time. Two alternative specifications are considered in our empirical analysis: 1) $f_{t}$ is a linear function of debtGNP ratio, and 2) $f_{t}$ is a step function of time. The first case corresponds to Barro's tax smoothing policy according to which the permanent components of the tax policy should be adjusted continually in response to the debt level. The policy rule implied by the second case is consistent with the recent political economy literature that emphasizes delayed fiscal adjustments due to political

\footnotetext{
7 For example, government expenditures on an existing program may be a function of the shocks, $\mathbf{a}_{\mathbf{0}}^{\prime} X_{t}$, and the government responses to the shocks by setting the taxes equal to $\mathbf{a}_{\mathbf{1}}^{\prime} X_{t}$. Then, $\mathbf{a}=\mathbf{a}_{\mathbf{0}}+\mathbf{a}_{\mathbf{1}}$. In principle, these parameters may not be constant over time.

8 This could be due to the costs associated with adjusting the surplus to the government's long-run target levels.
} 
or institutional constraints.

\subsection{The Contribution of Fiscal Shocks to the Primary Surplus}

To determine the quantitative importance of exogenous shocks to the variation of the primary surplus, we first run a simple linear regression of the surplus-GNP trend ratio, $s_{t}$ on the shock variables $X_{t}$. The result is reported in the first column of Table 1 . Although the Durbin-Watson statistic suggests there is serial correlation in the residuals, this regression illustrates the striking fact that almost $70 \%$ of the variation in the surplus can be replicated by a simple linear combination of the asset returns. When we include a lagged dependent variable, as in the second column, the specification of the model improves, but it does not add much in terms of its explanatory power. Moreover, the parameters of the model are quite robust to its inclusion. ${ }^{9}$

Figure 1 shows that there appears to have been a shift in the mean of the residuals during the mid-1980s. After this point, although the model continues to replicate the direction of movements in the surplus, it understates its true level. This is consistent with a level shift in the permanent components of the government's fiscal policy. The CUSUM test (which is a t-statistic testing for structural stability) reported in the table shows that the null of no structural change is rejected at the $5 \%$ level.

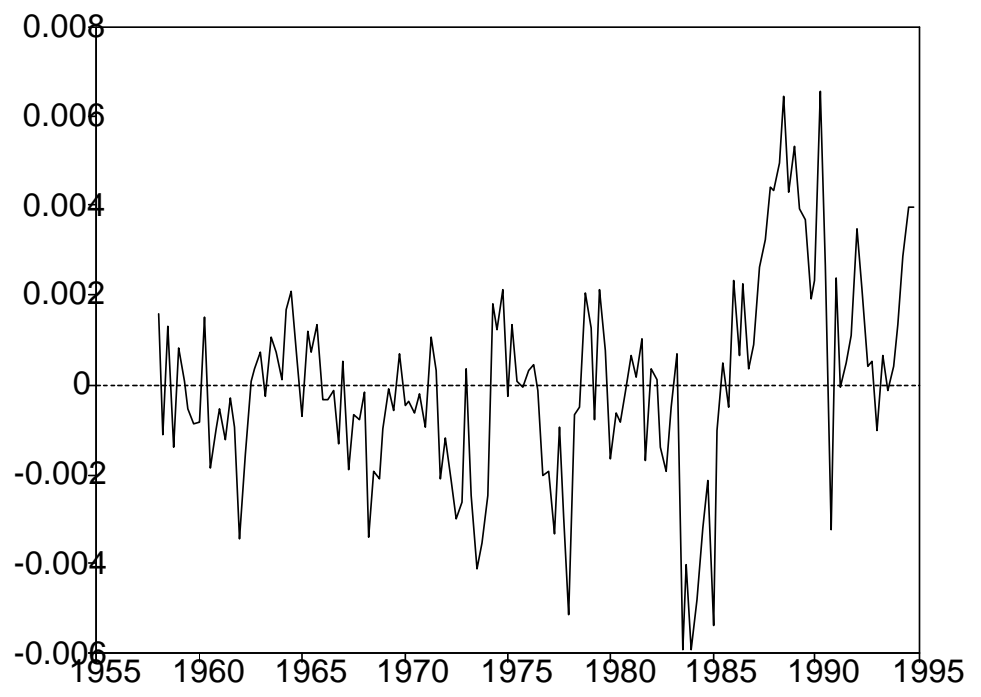

Figure 1: Residuals from Surplus Regression

\footnotetext{
9 As a comparison, we also report the same regressions by using the change in real GNP growth and the unemployment rate, instead of $X_{t}$, as shock variables. The results show that a much smaller portion of the variation in the surplus can be explained by these traditional shock variables (see Appendix).
} 


\subsection{The Shift in Fiscal Stance}

There are several reasons to suspect that there may have been a significant change in the fiscal stance of the Canadian government during the 1980s. These include the rapidly rising debt, the associated pressure from financial markets and a shift to a more conservative role for government. In the third column of Table 1, we include the debt-GNP ratio (DEBT) as an additional regressor to see if the structural change(s) can be explained by a continuous response of the fiscal policy to the rising debt, as suggested by the Barro's tax smoothing theory. Although DEBT is indeed a statistically significant regressor, there is still evidence of structural change as indicated by the CUSUM test.

An alternative to Barro's tax smoothing theory is the war of attrition model of Alesina and Drazen (1991), which emphasizes the political costs of adjusting fiscal policy. According to this theory, fiscal response to the rising debt may be delayed due to conflicts among different groups about how the burden of the required policy change is to be shared. Because of the delay, the change in the government's fiscal policy is better described by a discrete regime change. Here we identify the potential regime change by estimating the following switching regression model:

$$
s_{t}= \begin{cases}c_{1}+\mathbf{a}_{1}^{\prime} X_{t}+\rho_{1} s_{t-1}+\varepsilon_{1 t}, & \text { if } t \leq t^{*} \\ c_{1}+\mathbf{a}_{2}^{\prime} X_{t}+\rho_{2} s_{t-1}+\varepsilon_{2 t}, & \text { if } t>t^{*}\end{cases}
$$

where $\varepsilon_{1 t} \sim N\left(0, \sigma_{1}^{2}\right), \varepsilon_{2 t} \sim N\left(0, \sigma_{2}^{2}\right)$ and $t^{*}$ is unknown. We use the maximum likelihood method to estimate both the parameters and the break point $t^{*}$. The estimated $t^{*}$ is the second quarter of 1985. Figure 2 illustrates the maximized log-likelihood function (conditional on $t^{*}$ ) for different switching dates. This figure illustrates quite clearly why maximum likelihood estimation pinpoints the structural break as having occurred between the first and second quarter of 1985 . We test the significance of a structural break at this date with Chow tests for each of the regressions models discussed above. As can be seen this hypothesis cannot be rejected at the 5\% level.

To examine further the nature of this regime switch we re-run the regression reported in column 3 of Table 1 by introducing a dummy variable which takes on the value one after 1985:1 and zero otherwise. The fourth column of Table 1 documents this regression. When we account for the structural break in this way, the debt-GNP ratio is no longer a significant explanatory variable. This suggests that its significance in the previous regression was not the result of a stable relationship over shorter sub-periods. Indeed, when we estimated the regression within each regime, the debt-GNP ratio was no longer significant. ${ }^{10}$ Our preferred model is therefore represented by the regression model documented in the last column of Table 1 . It corresponds to a special case of (1) when $f_{t}$ is a step function of time that has an upward step at the second quarter of 1985.

To test the stability of the parameters on the shocks and the lagged surplus across the two regimes,

10 The reason for the significance we found in the previous regression seems to stem from the fact that both the surplus and the debt has moved upward during 1980s. 


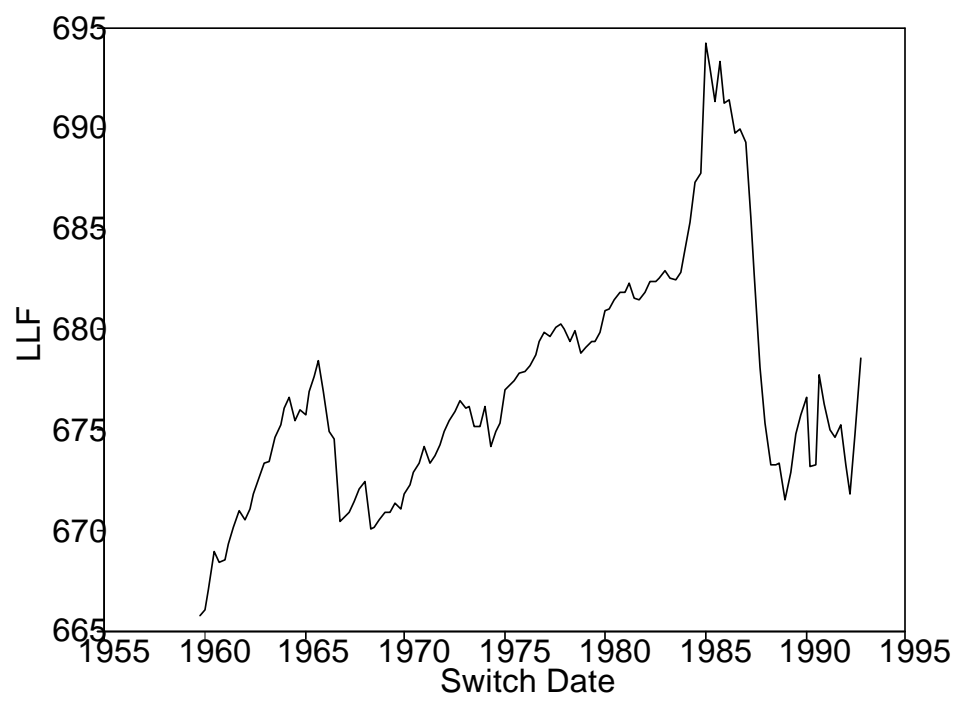

Figure 2: Log Likelihoood Function

we also regressed the residuals from our preferred regression on the explanatory variables within each regime. We could not reject the joint hypothesis that these parameters are constant across regimes. In other words, the change in policy stance is largely consistent with an increase in the permanent components of the surplus after the first quarter of 1985 rather than a change in the marginal responsiveness of the surplus to the exogenous shocks. ${ }^{11}$

Based on these empirical results, we can interpret the Canadian government's surplus process as follows: Under the fiscal policy rule that was in place in the 1960s and 1970s, the exogenous fiscal shocks accounted for about $70 \%$ of the variation in the primary surplus. Until the mid-1970s, the combination of the policy rule and the shocks had resulted in positive surpluses on average. Beginning in the mid-1970s, however, the exogenous shocks caused a sustained period of deficits and resulted in the rising debt under the original policy rule. Instead of adjusting its fiscal policy immediately in response to the deficits and rising debt, the government continued the original policy until 1985 when it adjusted the surplus level upward permanently. This adjustment, along with more favorable exogenous shocks, resulted in a return to positive primary surpluses in the late 1980s and early 1990s. The behavior of the Canadian primary surplus therefore appears to be more consistent with the political economy model of Alesina and Drazen (1991) than with the tax smoothing model of Barro (1979).

11 As we show below, a forecast of the surplus in the latter half of the sample using data from the first half of the sample tracks the actual surplus quite well (see Figure 2). This suggsts that the high $R^{2}$ is not due to overfitting. 


\section{Fiscal Risk Management}

The analysis of the previous section raises some intriguing questions: Given that much of the variation in the surplus can be replicated by the return on a portfolio of international securities, could the government mitigate the impact of these fiscal shocks by hedging the risk? Moreover, under what conditions would such a policy be desirable? In this section, we investigate the potential role for systematic fiscal risk management as part of the government's overall debt policy. To do so, we develop a framework for analyzing the impact of the government's fiscal policy on welfare that is consistent with the international asset pricing model that we use for determining the cost of hedging.

\subsection{A Small Open Economy}

Consider a small open economy populated with a large number of identical, infinitely-lived households. Time is discrete. Let $z_{t}$ be the state variable that summarizes the exogenous shocks in period $t$, and $z^{t}=\left(z_{0}, z_{1}, \ldots z_{t}\right)$ be the history of shocks up to period $t$. We assume that there is a complete world financial market in which all contingent claims with payoffs that are a measurable function of $z^{(t)}$ can be traded. Under this assumption and the assumption of no-arbitrage, there exists a sequence of stochastic discount factors, $\left\{M_{t}\right\}_{t \succeq 0}$, such that the time $t$ price of a contingent claim that pays $f\left(z^{(t+j)}\right)$ in period $t+j$ is ${ }^{12}$

$$
\Pi_{t}(f)=E_{t}\left[\frac{M_{t+j}}{M_{t}} f\left(z^{(t+j)}\right)\right]
$$

The small open economy assumption implies that the stochastic discount factors are exogenous with respect to domestic agents' actions. In particular, changes in the domestic government's fiscal policy has no effect on them.

The domestic households' preferences over the consumption plan $\underline{c}=\left\{c_{t}\right\}_{t \succeq 0}$ are represented by a utility function $U(\underline{c})$. Here, we do not impose any restrictions on $U($.$) except that it is concave and$ that, for any $\underline{c}$ and $\delta>0, U(\underline{c}+\delta)>U(\underline{c})$, where $\underline{c}+\delta$ is defined as $\left\{c_{t}+\delta\right\}_{t \succeq 0}$. In particular, $U($.) can be the same or different from those of the foreign investors and it can represent non-expected utility, as in Epstein and Zin (1989), or time non-separable utility, as in Abel (1990). Our welfare measure defined below is independent of these considerations.

The representative household in the domestic economy is endowed with the following concave production technology:

$$
y_{t}=A_{t} k_{t}^{\alpha}, \quad 0<\alpha<1,
$$

where $y_{t}$ and $k_{t}$ are the period $t$ output and capital input, respectively, and $A_{t}$ is the domestic productivity, which grows at a constant rate $\xi$, i.e. $A_{t}=A_{0} e^{\xi t}$. The capital investment decision is made one period ahead but can be state contingent. Thus, in period $t$, the household commits to a state

12 See, for example, Harrison and Kreps (1979). 
contingent investment plan by buying a contingent claim $k_{t+1}\left(z^{(t)}, z_{t+1}\right)$. For simplicity we assume full depreciation. The government taxes this output at the rate $\tau_{t}$. In each period, the household allocates her after-tax output between consumption, capital investment and investment in financial contingent claims. Let $c_{t}$ and $b_{t+1}\left(z^{(t)}, z_{t+1}\right)$ denote the household's consumption and contingent claim holding in period $t$, respectively. Then, the household's budget constraint in period $t$ is

$$
c_{t}+E_{t}\left[\frac{M_{t+1}}{M_{t}}\left(b_{t+1}\left(z^{(t)}, z_{t+1}\right)+k_{t+1}\left(z^{(t)}, z_{t+1}\right)\right)\right] \leq\left(1-\tau_{t}\right) A_{t} k_{t}^{\alpha}+b_{t} .
$$

Under the complete market assumption, Fisher separation applies with respect to the household's consumption and production decisions. Let

$$
W_{0}=\frac{1}{M_{0}} \sum_{t=0}^{\infty} E_{0}\left[M_{t}\left(1-\tau_{t}\right) A_{t} k_{t}^{\alpha}-M_{t+1} k_{t+1}\right] .
$$

denote the household's wealth at time zero. Then, for any given level of $W_{0}$, the household's welfare is

$$
V_{0}\left(W_{0}\right)=\max _{\underline{c}}\left\{U(\underline{c}), \text { s.t. } \frac{1}{M_{0}} \sum_{t=0}^{\infty} E_{0} M_{t} c_{t} \leq W_{0}\right\} .
$$

In particular, the government's fiscal policy affects the household's welfare only through its impact on current wealth $W_{0}$. Thus, from now on, we will refer to $W_{0}$ as the household's welfare. As we mentioned above, this welfare measure is independent of the specification of the preference for the domestic households. Therefore, any welfare gains from fiscal risk management must come from increasing the domestic household's wealth, not from smoothing the household's consumption profile.

For any given fiscal policy, the household chooses her investment decision to maximize her production wealth, $W_{0}$. It is straightforward to show that the optimal investment rule is given by

$$
\hat{k}_{t+1}=\left[\alpha\left(1-\tau_{t+1}\right) A_{t+1}\right]^{\frac{1}{1-\alpha}}
$$

so that the household's maximized wealth is

$$
\hat{W}_{0}=\left(1-\tau_{0}\right) A_{0} k_{0}^{\alpha}+\alpha^{\frac{\alpha}{1-\alpha}}(1-\alpha) \frac{1}{M_{0}} \sum_{t=1}^{\infty} E_{0} M_{t}\left[\left(1-\tau_{t}\right) A_{t}\right]^{\frac{1}{1-\alpha}} .
$$

Given a joint distribution over future fiscal policy and the stochastic discount factor, (9) can be used to compute aggregate expected wealth. With complete markets, changes in wealth provide a compensating variation measure of welfare, that is independent of domestic preferences. Note that this welfare function is a stochastic version of the welfare function used in the original tax smoothing paper by Barro (1979). However, instead of assuming that the costs of revenue collection per period as a time-invariant convex function of the tax rate, here we derive the welfare function from the fundamentals. In this sense, we provide a microfoundation for the welfare function used by Barro. 


\subsection{The Government s Fiscal Policy}

Government expenditure in period $t$ is $G_{t}=G_{t}\left(z_{t}\right)$. We assume that $\left\{G_{t}\right\}_{t \succeq 0}$ is an exogenous stochastic process. The government's primary surplus in period $t$ is then

$$
S_{t}=\tau_{t} A_{t} \hat{k}_{t}^{\alpha}-G_{t}\left(z_{t}\right)=\alpha^{\frac{\alpha}{1-\alpha}} A_{t}^{\frac{1}{1-\alpha}} \tau_{t}\left(1-\tau_{t}\right)^{\frac{\alpha}{1-\alpha}}-G_{t}\left(z_{t}\right) .
$$

Let $\bar{y}_{t}=y_{0} e^{\frac{\xi}{1-\alpha} t}=A_{0} k_{0}^{\alpha} e^{\frac{\xi}{1-\alpha} t}=A_{0}^{-\frac{\alpha}{1-\alpha}} k_{0}^{\alpha} A_{t}^{\frac{1}{1-\alpha}}$ be the trend GNP, $s_{t}=S_{t} / \bar{y}_{t}$, and $g_{t}=G_{t}\left(z_{t}\right) / \bar{y}_{t}$. Also, define the "effective tax rate" as $\theta_{t}=\tau_{t}\left(1-\tau_{t}\right)^{\frac{\alpha}{1-\alpha}}\left(A_{0} \alpha\right)^{\frac{\alpha}{1-\alpha}} / k_{0}^{\alpha}$. The implied primary surplus-trend GNP ratio can then be expressed as

$$
s_{t}=\theta_{t}-g_{t}\left(z_{t}\right)
$$

Note that because of the production distortion, there is a Laffer curve associated with the collection of tax revenue. The maximum revenue that can be raised occurs when $\tau=1-\alpha$, or when the effective tax rate is given by

$$
\bar{\theta}=(1-\alpha) \alpha^{\frac{2 \alpha}{1-\alpha}} A_{0}^{\alpha} / k_{0}^{\alpha}
$$

The expression of the equilibrium primary surplus process in (11) is consistent with the empirical specification we used in section 2 with $\rho=0$. In fact, if we assume that

$$
g\left(z_{t}\right)=\bar{g}-\mathbf{a}^{\prime} \mathbf{X}_{t}-\varepsilon_{t},
$$

where $\bar{g}$ denotes the mean government spending to trend GNP ratio, then, it follows that the permanent component of the government's policy variables (the first term in 1) can be represented as

$$
f_{t}=\theta_{t}-\bar{g}
$$

Thus, a change in $f_{t}$ corresponds to a change in the effective tax rate $\theta_{t}$.

If the government could issue state-contingent debt, then it can be easily shown that the optimal tax policy would imply a constant effective tax rate across time and states. However, if the government can only issue risk-free debt, a constant tax rate may result in a debt path that is unsustainable. To ensure sustainability in this case, a policy rule has to be specified to determine how the tax policy will change in response to the rising debt. In the following, we consider a policy rule that is consistent with the empirical behavior of the primary surplus we reported in section 2 .

Let $D_{t}(\theta)$ be the level of government debt at the end of period $t$ when the effective tax rate in period $t$ is $\theta$. Then, we have

$$
D_{t}=\left(1+r_{t-1}\right) D_{t-1}-\left[\theta-g_{t}\left(z_{t}\right)\right] \bar{y}_{t} .
$$


where $r_{t}$ is the effective interest rate on government debt. We also define

$$
V_{t}(\theta)=\frac{1}{M_{t}} \sum_{j=1}^{\infty} E_{t} M_{t+j}\left[\theta-g_{t}\left(z_{t}\right)\right] \bar{y}_{t}
$$

to be the present value of the government's primary surpluses if the tax rate continues to be $\theta$ in the future. We define the "net debt" as the debt minus the present value of future surpluses under the existing tax policy, $D_{t}-V_{t}\left(\theta_{0}\right)$.

We assume that the government faces an upper bound, $\phi$, on the net debt-trend GNP ratio. The effective tax rate will remain at its "normal" level, $\theta_{0}$, as long as the net debt-trend GNP ratio is below the upper bound. Whenever the ratio reaches or exceeds the upper bound, the tax rate is raised to a "crisis" level, $\theta^{*}$, until the net debt, evaluated under the normal tax regime, falls to zero. At this point the effective tax rate is set back to its normal level. Thus, if the effective tax rate in period $t$ is $\theta_{t}$, then,

$$
\theta_{t+1}= \begin{cases}\theta_{0} & \text { if } \theta_{t}=\theta_{0} \text { and } D_{t}-V_{t}\left(\theta_{0}\right)<\phi \bar{y}_{t} \\ \theta^{*} & \text { if } \theta_{t}=\theta_{0} \text { and } D_{t}-V_{t}\left(\theta_{t}\right) \geq \phi \bar{y}_{t} \\ \theta_{0} & \text { if } \theta_{t}>\theta_{0} \text { and } D_{t}-V_{t}\left(\theta_{0}\right) \leq 0\end{cases}
$$

where $\theta^{*}$ is set high enough so that the net debt declines on average over time:

$$
D_{t}-V_{t}\left(\theta_{t+1}^{*}\right)<0 \text {. }
$$

The level at which the crisis tax rate is set determines the average speed with which the net debt is reduced, and the normal tax regime is resumed. Given this policy rule, we can then evaluate the impact of risk management on welfare. ${ }^{13}$

\subsection{Hedging Strategy and Its Evaluation}

Without hedging, the government debt evolves according to the following equation:

$$
D_{t}-D_{t-1}=r_{t-1} D_{t-1}-S_{t}=r_{t-1} D_{t-1}-\left[\theta_{t}-\bar{g}+\mathbf{a}^{\prime} \mathbf{X}_{t}+\varepsilon_{t}\right] \bar{y}_{t} .
$$

For a given effective tax rate, the debt may increase rapidly if the surplus process experiences a large negative shock - an unusually low value of $\mathbf{a}^{\prime} \mathbf{X}_{t}$. Ex ante, the government can avoid these negative shocks through hedging. Suppose that, at some date $t$, the government adopts a very simple hedging strategy — replacing the volatile component of the primary surplus, $\mathbf{a}^{\prime} \mathbf{X}_{\tau} \bar{y}_{\tau}$, with a deterministic cash-flow that is a constant percentage of the trend GNP, $\bar{s}$, and which has the same present value. ${ }^{14}$

\footnotetext{
13 Although this policy rule is consistent with our empirical observations in Section 2, it is not unique.

14 Since the US dollar value of $X_{t}$ is determined in the US financial market and is independnt of the Canadian government's actions, there are no transactions costs due to the potential for the government to partially default on its liabilities by inflating.
} 
The government can do this by holding a portfolio whose payoff in period $\tau>t$ is

$$
h\left(\mathbf{X}_{\tau}, \tau\right)=\left(\bar{s}-\mathbf{a}^{\prime} \mathbf{X}_{\tau}\right) \bar{y}_{\tau}
$$

or by entering into an Index-Linked-Swap with investors, with the floating index being $\mathbf{a}^{\prime} \mathbf{X}_{\tau} \bar{y}_{\tau}{ }^{15}$ For the portfolio to be self-financing, the cash flow $\bar{s}$ must satisfy

$$
\bar{s}=\frac{\sum_{\tau>t}^{\infty} E_{t}\left[M_{\tau} \mathbf{a}^{\prime} \mathbf{X}_{\tau} \bar{y}_{\tau}\right]}{\sum_{\tau>t}^{\infty} E_{t}\left[M_{\tau} \bar{y}_{\tau}\right]} .
$$

Under this hedging strategy, the process that governs the evolution of the government debt becomes

$$
D_{\tau}-D_{\tau-1}=r_{\tau-1} D_{\tau-1}-\left[\theta_{\tau}-\bar{g}+\bar{s}+\varepsilon_{\tau}\right] \bar{y}_{\tau}
$$

for $\tau>t$. Under hedging the debt process is less volatile. However, whether the net debt is less likely to hit the upper bound under hedging depends on the value of $\bar{s}$, which reflects the financial cost of hedging - the risk premium that must be paid to investors. If hedging is costless, then the government should be able to replace the cash flow $\mathbf{a}^{\prime} \mathbf{X}_{\tau} \bar{y}_{\tau}$ with its expected value $E_{t}\left[\mathbf{a}^{\prime} \mathbf{X}_{\tau} \bar{y}_{\tau}\right]$. Thus, the difference between the expected value and the actual payment it receives, $E_{t}\left[\mathbf{a}^{\prime} \mathbf{X}_{\tau} \bar{y}_{\tau}\right]-\bar{s} \bar{y}_{\tau}$ represents the financial cost of hedging. Since the vector $\mathbf{X}_{\tau}$ is demeaned its expected value equals zero, so the hedging cost is effectively indexed by $\bar{s}$. When the hedging cost is high the value of $\bar{s}$ could be very low or even negative ${ }^{16}$, and the debt may grow faster under hedging.

In order to quantify the hedging cost and to evaluate domestic households' welfare, we need to specify a joint stochastic process for the discount factor $M_{t}$ and the state variable $\mathbf{X}_{\mathbf{t}}$. We assume that the vector $\tilde{\mathbf{X}}_{t}$, which consists of the asset returns VWR, DIV, TBILL and LONGR, follows a vector autoregressive (VAR) process:

$$
\tilde{\mathbf{X}}_{t}=\mathbf{A} \tilde{\mathbf{X}}_{t-1}+\mathbf{u}_{t}
$$

where $\mathbf{A}$ is a matrix of coefficients and $\mathbf{u}_{t} \sim N(\mathbf{0}, \boldsymbol{\Sigma})$. Note that the vector $\tilde{\mathbf{X}}_{t}$ does not include one of the factors we used in $\mathbf{X}_{t}$ - TBMA, the one-year moving average of TBILL. However, given the estimated process for the asset returns, the value of TBMA can be easily constructed. The process is estimated using quarterly data from 1958:1 to 1994:4.

We also assume that the growth rate in the stochastic discount factor, $\mu_{t}=\log \left(\frac{M_{t}}{M_{t-1}}\right)$ is a linear function of the lagged state variables given by

$$
\mu_{t}=\mathbf{c}^{\prime} \tilde{\mathbf{X}}_{t-1}+\eta_{t}
$$

where $\eta_{t}$ is $N\left(0, \sigma_{\eta}^{2}\right), E_{t-1}\left[\varepsilon_{t} \eta_{t}\right]=0$ and $E_{t-1}\left[\mathbf{u}_{t} \eta_{t}\right]=\mathbf{v}$. The effective interest rate on government

\footnotetext{
15 Various kinds of Index-Linked-Swaps have now been widely traded by many financial institutions, although not with infinite maturity. We discuss the potential problems of implementing such a swap in the conclusion.

16 That is, to shift the risky cash flow to the investors, the government may receive in return only a very small amount of deterministic cash flow or even have to pay the investors.
} 
debt $r_{t}$ is also assumed depend on lagged state variables:

$$
r_{t}=\mathbf{B} \tilde{X}_{t-1}+b r_{t-1}+\zeta_{t}
$$

where $\zeta_{t} \sim N(0, \sigma)$. This, together with the estimated processes for the asset returns (23) and the stochastic discount factor (24), represents a restricted VAR.

Because the stochastic discount factor is not directly observable, an asset pricing model is needed to estimate equation (24). There are several consumption-based asset pricing models that we could use, none of which is perfect. In this paper, we adopt the consumption CAPM based on the nonexpected utility model proposed by Epstein and Zin (1989) and Weil (1989). We choose this asset pricing model for two reasons: 1) Studies have shown that it performs better than the standard consumption CAPM based on additively separable utilities, and 2) there are micro studies that provide us with some sense about the range of values that the parameters should take. ${ }^{17}$ Like most other consumption CAPM models, it is difficult for the Epstein-Zin model to generate realistic risk-premiums with plausible parameter values. This suggests that the hedging cost implied by the model may be too low. To check the robustness of our results, we vary the hedging cost independently in evaluating welfare gains. In addition, we also report results based on an alternative asset pricing model — Abel's (1990) "Catching up with Joneses" model.

The stochastic discount factor implied by the Epstein-Zin model is

$$
\tilde{M}_{\tau}=\left(\beta^{\tau} C_{\tau}^{-\frac{1}{\sigma}}\right)^{\theta}\left(\Pi_{s=0}^{\tau} \frac{1}{R_{s}^{m}}\right)^{1-\theta} .
$$

Here, $C_{\tau}$ denotes the US per capita consumption, $R_{t}^{m}$ denotes the gross real return on the market portfolio (measured by the real value-weighted stock return index on the NYSE), $\sigma$ is the elasticity of intertemporal substitution, and $\theta$ is defined, following Campbell (1993), as

$$
\theta=\frac{1-\gamma}{1-(1 / \sigma)}
$$

where $\gamma$ is the coefficient of relative risk aversion. The variable $\tilde{M}_{\tau}$ is a real stochastic discount factor that can be used to price contingent claims in real US good units. To price cash-flows in Canadian dollars, the appropriate stochastic discount factor is $M_{\tau}=\tilde{M}_{\tau}\left(P_{\tau} e_{\tau}\right)^{-1}$, where $P_{\tau}$ is the US CPI and $e_{\tau}$ is the nominal exchange rate.

Given the domestic production technology, fiscal policy rule and the asset pricing model specified above, we can now evaluate the implications of fiscal risk management on fiscal policy, sustainability and welfare.

17 See Kocherlakota (1995) for a review of asset pricing models. 


\subsection{Calibration}

Production function: We set $\alpha=0.33$ and assume that the initial capital stock $k_{0}$ has been chosen optimally, so that $k_{0}=\left[\alpha\left(1-\tau_{0}\right) A_{0}\right]^{\frac{1}{1-\alpha}}$.

Asset Pricing Model: We follow others in the literature by setting $\beta=0.99$. For each value of $\gamma$ we set $\sigma$ so that the implied steady-state risk free quarterly nominal interest rate is fixed at $3 \%$. For a coefficient of risk-aversion $\gamma=4$, this calibration yields a value for the marginal rate of substitution of $\sigma=0.53$. Although, there is widespread disagreement regarding the appropriate values of $\gamma$ and $\sigma$, we adopt these values for our benchmark economy because they are in the range that most observers seem to find acceptable (see Kocherlakota, 1996). However, in the following analysis, we evaluate the hedging strategy under several different combinations of parameter values. Given these parameter values and the VAR described above, it is straightforward to price the components of the surplus and, hence, to determine the value of $\bar{s}$ (see appendix for details). ${ }^{18}$

Fiscal Policy Rule: For the policy rule to be fully specified, we must choose values for $\theta_{0}, \theta^{*}$ and $\phi$. From (14) and the regression analysis in section 2, we have that

$$
\theta_{t}-\bar{g}=f_{t}= \begin{cases}c_{1}=.006514, & \text { if } t \leq t^{*} \\ c_{2}=.016453, & \text { if } t>t^{*}\end{cases}
$$

We interpret $c_{1}+\bar{g}$ as the normal tax rate $\theta_{0}, c_{2}+\bar{g}$ as the emergency tax rate $\theta^{*}$ and $t^{*}$ as the time when the net debt-trend GNP ratio hit the boundary $\phi$. Thus, under the normal tax regime, the primary surplus process evolves according to the following equation

$$
s_{t}=c_{1}+\mathbf{a}^{\prime} X_{t}+\varepsilon_{t},
$$

where the values of $\mathbf{a}$ is determined from the regression analysis in section 2 . From the asset pricing model specified above we can determine the present value $V_{t^{*}}\left(\theta_{0}\right)$, and the value of $\phi$ is then set to be the net debt-trend GNP ratio at $t^{*},\left(D_{t^{*}}-V_{t^{*}}\left(\theta_{0}\right)\right) / \bar{y}_{t^{*}}$. Given our estimate that the shift in policy stance occurred after the first quarter of 1985, the implied value of the upper bound on the net debt/trend GNP ratio, $\phi$, is about 0.80 . We use this value for our benchmark economy, but consider the sensitivity of our results to alternative values.

Initial Conditions: We take the perspective of a government that starts to hedge in 1977:1 and has only the information available up to the last quarter of 1976. The sixth column of Table 1 (titled "pre-77") documents the results of estimating the model over the period 1958:1 to 1976:4. As can be seen the coefficient estimates are quite robust to this truncation of the sample period. The fact that we are able to identify the replicating portfolio ex ante suggests that our empirical specification should provide a useful basis for hedging the shocks to the surplus. Indeed, as Figure 3 illustrates,

18 Details of the results from estimating this VAR, can be found in the the appendix. 
a forecast conditional on the realized asset returns and the shift in policy stance, performs rather well in replicating the actual surplus in the post-sample period 1977:1 to 1994:4. This conditional forecast replicates over $80 \%$ of the variation in the surplus.

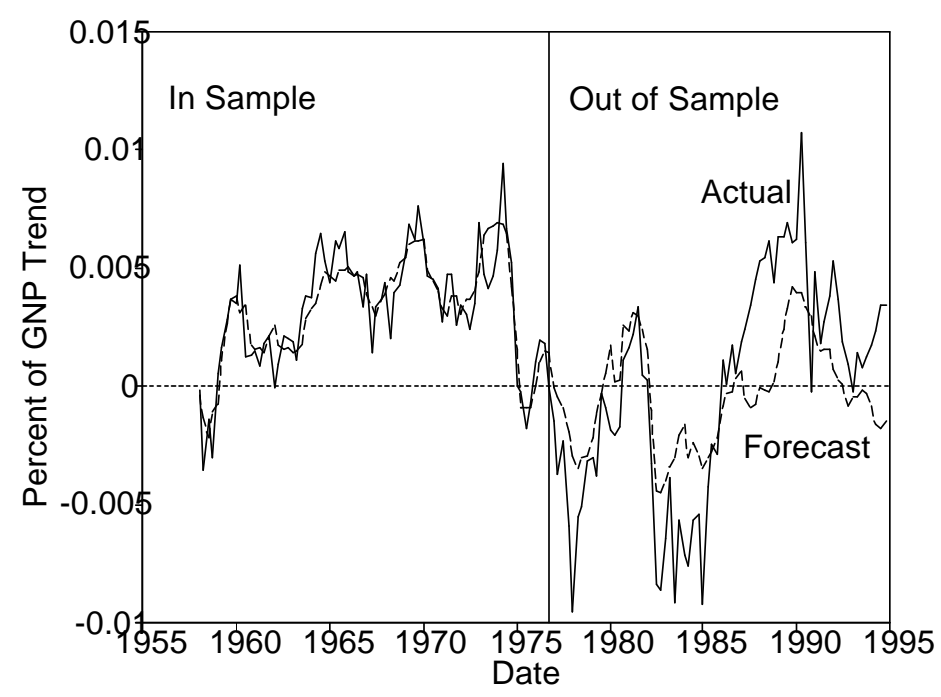

Figure 3: Forecasting the Primary Surplus

\subsection{Results}

Using the data from our simulation, we estimate the probability that the initial policy first becomes unsustainable and the government is forced to raise the tax rate. To do this we counted the number of paths along which the tax is increased for the first time. Figure 4 shows the evolution of this probability after $t=1977: 1$ both with and without hedging. Without hedging, the probability that the original policy rule would have become unsustainable within the following 100 quarters (i.e. by the last quarter of 2002), is $Q(100)=0.36$. With hedging it drops to $Q_{H}(100)=0.05$. In other words, had the government begun to use this simple risk management strategy in the first quarter of 1977, it would have reduced the ex ante probability that its policy would become unsustainable at some time before the end of 2002 , by over $85 \%$. But what does this increased sustainability imply for the expected tax rate and welfare?

Figure 5 shows the average tax rates that result from the policy rule in the benchmark economy, with and without hedging over 150 years. As can be seen, the expected tax rates rise initially in both cases. This is because the net debt is initially positive and hence trends upward on average. The 


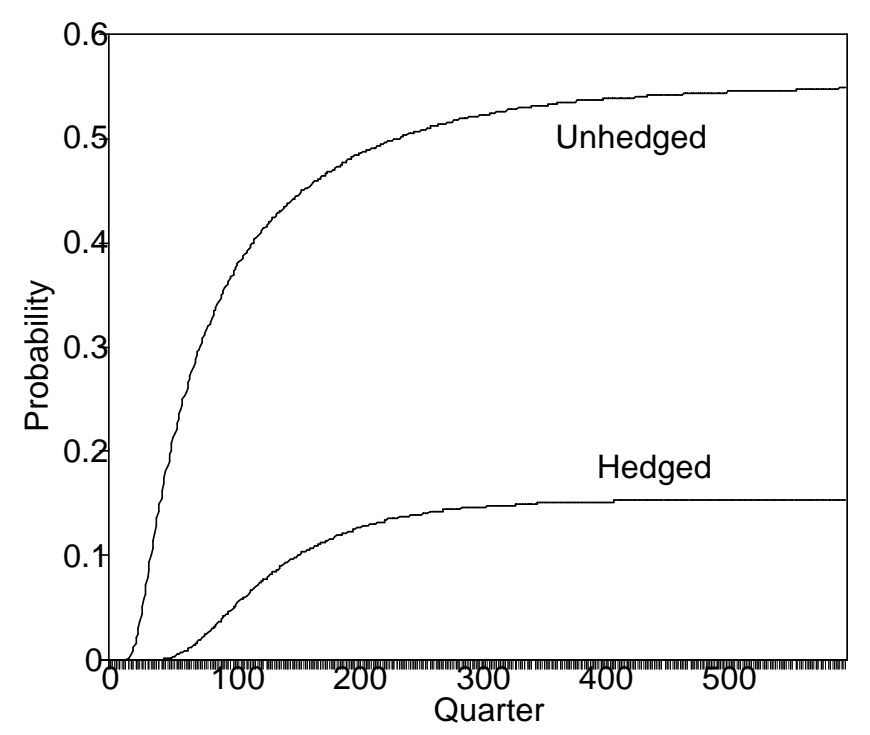

Figure 4: Sustainability of Initial Policy

average tax rate rises less rapidly with hedging than without, reflecting the reduced likelihood of hitting the upper bound on the net debt level. Once the tax has been increased, the net debt begins to decline on average so that eventually, the tax rate can be reduced to its "normal level". Over time there are more paths realizing falling taxes on average than there are paths realizing rising taxes, so that the average tax rate falls. ${ }^{19}$ In the long run, the tax rate remains lower under hedging because (1) the probability of having to increase taxes in the future is lower, and (2) the average rate at which the net debt is reduced once the tax is raised is greater.

We compute the welfare gain arising from hedging using (9). The first row of Table 2 shows the aggregate wealth levels with and without hedging, and the welfare change for the benchmark economy. In particular it shows the flow welfare change as a percentage of initial GNP and the percentage change in welfare. As can be seen the former increase is approximately $1.42 \%$ and the latter is $0.64 \%$.

In principle, this welfare gain could come from two sources: (1) the reduction in expected taxes and (2) the reduced variation in taxes via the concavity of the production function. However, by far the greatest part of the gain comes from the former. To show that this is the case we computed a first-order approximation to the welfare gain (see appendix) and found that over 99\% of the welfare

19 Note that even after the net debt is reduced to zero, some paths realize sufficiently bad shocks to make the net debt positive again and to eventually experience rising taxes again. However, the average tax rate still declines. 


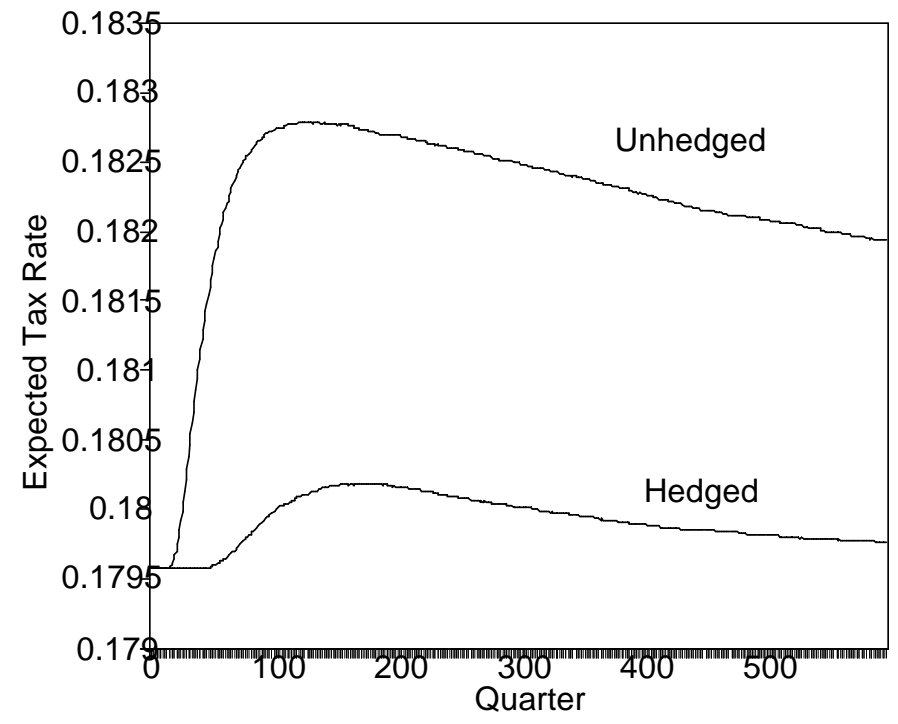

Figure 5: Expected Tax Rates

gain derives from the reduction in taxes. ${ }^{20}$ In other words, in our model, the gains from hedging come predominantly from the increased sustainability of the low tax policy.

To investigate the nature of these welfare gains further and to assess the sensitivity of our results to the various assumptions we have made, we allow the key underlying parameters to vary from our benchmark case. The results are given in Table 2 .

Risk Aversion $(\gamma)$ : We varied $\gamma$, while at the same time adjusting $\sigma$ to maintain the same long run risk-free interest rate. Results for $\gamma=2$ and $\gamma=10$ are shown in Table 2. As one might expect, raising risk aversion lowers welfare whether the government hedges or not. However, the welfare gain from hedging is non-monotonically related to the coefficient of risk-aversion, initially rising with $\gamma$ and then falling. ${ }^{21}$ There are several effects from raising $\gamma$ :

- The risk premium required by the representative investor increases. This drives up the financial cost of hedging (a reduction in $\bar{s}$ ), which feeds into higher expected taxes under hedging, thereby reducing the welfare gain.

- The market value of the increase in domestic wealth rises. These is because as $\gamma$ is increased, the elasticity of intertemporal substitution, $\sigma$, must be reduced to maintain a constant risk-free interest rate. It follows that the value of increasing the sustainability of the low tax policy (i.e. delaying the tax hike) rises, so that the welfare gain from hedging increases.

20 This is generally the case under all of the alternatives considered below.

21 The turning point in this relationship occurs approximately when $\gamma=7$. 
- The present value of future surpluses under the initial policy, $V\left(\theta_{0}\right)$, decreases. The resulting higher initial net debt reduces the sustainability of the initial tax policy and reduces the welfare gain.

To separate the effects of changing risk preferences from that of changing initial conditions, we also report in Table 2 results for $\gamma=2$ and $\gamma=10$ when the debt level is adjusted so that the initial net debt is the same as that for $\gamma=4$. After controlling for the initial net debt in this way, the welfare gain increases monotonically with risk aversion. This shows that the increase in the hedging cost due to the increase in risk aversion is more than compensated for by the gains from the increased sustainability of the initial low tax policy.

edging Cost $(-\bar{s})$ : To isolate the role of the increase in financial cost of hedging from other aspects of the increase in risk aversion, we fixed $\gamma$, but varied the hedging cost directly, so that it would equal the cost associated with lower or higher values of $\gamma$. As can be seen, raising this hedging cost lowers the welfare gain unambiguously. If it is raised enough, the welfare gain eventually becomes negative. Note, however, that within a range consistent with the Epstein-Zin CAPM, the hedging cost is never really high enough to have much impact on the welfare gain. This is consistent with the inability of the model to account for the equity-premium puzzle.

Initial et ebt $\left(D_{0}-V_{0}\left(\theta_{0}\right)\right)$ : In the benchmark case, the initial net debt-GNP trend ratio is 0.28 . Lowering it to zero raises welfare because the reduction makes the need for a tax hike less imminent (as indicated by the low probability of a tax hike within the first 100 quarters, $Q(100)$ ). Lowering the net debt also raises slightly the welfare gain from hedging. Increasing the net debt to 0.799 , so that it makes an immediate tax hike very likely, lowers welfare and significantly reduces the welfare gain from hedging. In this case, hedging actually increases the probability of a tax hike. With a high initial level and a strictly positive effective interest rate the net debt is expected to rise and hit the upper bound quickly, and hedging reduces the chance of having positive shocks to the surplus that would help to revert the upward trend. Interestingly, however, there are still significant welfare gains from hedging, reflecting the more rapid reduction in the net debt under hedging following the first tax increase and the lower likelihood of further tax hikes in the future.

Starting ate $\left(t_{0}\right)$ : The starting date for the adoption of the hedging strategy in the benchmark economy, $t_{0}=1977: 1$, was approximately in the middle of the sample. This is a date at which the debt level and the realized values of the asset returns are such that the initial net debt is well below the trigger point and the hedging cost takes on a relatively low value. We also ran our simulation with a starting date of $t_{0}=1985: 1$. As noted above this is a date at which the net debt is just about to exceed the upper bound and it is also a date such that the implied cost of hedging is high. The combination of these two factors reduces the welfare gain from hedging significantly. Note, however, that the welfare gains are still positive because of the more rapid reduction in the net debt 
under hedging following the first tax increase, and the lower likelihood of further tax hikes in the future.

pper ound on the et ebt $(\phi)$ : Lowering the net debt-GNP ratio at which the government increases taxes to 0.60 raises the likelihood of tax increases, thereby raising the expected tax rate and lowering welfare. Raising $\phi$ to 1.00 has the opposite effects. Quantitatively, however, such changes in $\phi$ have very small effects on the welfare gains from hedging.

Alternative Asset Pricing Model: Since the Epstein-Zin model cannot generate realistic risk premiums with reasonable values of the parameters, we also consider an alternative asset pricing model to check the robustness of our results on welfare gains. The model we considered is Abel's (1990) Catching-up-with-the-Joneses CAPM. ${ }^{22}$ According to this model, individuals derive utility from how well they are doing relative to how well the average person is doing today and how well the average person did last period. The advantage of this model is that it allows an extra degree of freedom, so that the equity premium puzzle can be solved with low risk aversion parameters. As before, we calibrate so that the risk-free interest rate equals 3\%. Table 2 reports the results for two sets of parameter values. The first, denoted "Low Cost", represents parameter values for which the hedging cost is equal to that in the benchmark economy. The second, denoted "High Cost", represents parameter values such that the sensitivity of utility to per capita consumption is sufficiently large (according to Abel's results) to account for the equity premium. We found that the welfare gain ranges from $0.89 \%$ to $1 \%$ of current GNP. The robustness of our results across these alternative CAPMs is largely due to our underlying assumption that the discount factor is a log-linear function of the state-variables.

\subsection{When Should the Government Hedge ?}

An important implication of this sensitivity analysis is that initial conditions - especially the combination of net debt and hedging cost - matter. Our results should therefore not be taken to imply that hedging is always desirable. For low levels of initial net debt, hedging reduces the probability of tax increases and increases the welfare. When the initial net debt level is very high, however, hedging increases the probability of having an immediate tax hike, and the benefits of hedging tend to be small. If the hedging cost is also high, then hedging may actually reduce welfare. This does not imply, however, that the hedging strategy we have described should never be adopted when the hedging cost is high. It simply says that the net debt level must first be reduced, by traditional methods, to a sufficiently low level before the hedging strategy is adopted. It follows that the government should hedge only after they have put their fiscal house in order — fiscal risk management should

22 See Appendix for details. 
be viewed as a way of helping to avoid future debt problems, not as a method for solving current ones.

\section{Concluding Remarks}

The central premise of this paper is that government cash flows are subject to unavoidable fiscal shocks that are outside the control of the fiscal authorities. In this paper we replicate many of the shocks to the Canadian federal surplus using the return on a linear combination of US. financial securities. We find that it is possible to characterize the surplus process over the last four decades as a stationary function of these shocks with an abrupt regime shift in 1985. Our results are consistent with the hypothesis that the recent rise in public debt experienced by Canada was the result of a series of negative shocks in the 1970s and 1980s, and a long delay in the adjustment of fiscal policy in response.

Although some fiscal shocks could be offset by varying tax rates and other policy parameters, this would create further distortions in the economy. The alternative of intertemporal smoothing through debt financing is ultimately unsustainable. We have argued in this paper that, because of this conflict between stability and sustainability, systematic fiscal risk management might be beneficial as part of the government's overall debt management strategy. We explored the feasibility of this, and estimated the potential gains from fiscal risk management in terms of increased sustainability, reduced tax rates and welfare. Although, the increases in sustainability are large, the welfare gains are fairly modest (though quite robust). It should be noted, however, that some of our modeling assumptions are somewhat conservative. In particular, if we allowed for endogenous growth, then tax changes would have permanent effects, so that the welfare gains from hedging would be much larger.

In this paper, we have abstracted from several interesting and potentially important issues regarding the implementation of a fiscal risk management strategy. The hedging strategy that we considered requires the government to enter into an index-linked swap with an infinite maturity. It would be interesting to see if the strategy can be replicated with more conventional financial instruments. There is also the issue of default risk that is often associated with swaps of long maturity. In this paper we have dealt with this problem to some extent by having the payoffs of the swap denominated in US dollars. This eliminates the possibility of partial default by the Canadian government through inflation. Of course, this does not exclude the possibility of direct or indirect default by the government through other means, and it would be interesting to evaluate the welfare gains from hedging by taking into account credit risk explicitly. ${ }^{23}$ Finally, there is the issue of timeconsistency. In this paper we assume that once the government decides to implement the hedging

23 Note, however, that hedging should reduce the default risk premium already implicit in the effective interest rate on the debt, thereby offsetting the increased cost of hedging. 
strategy, it will stick to it in the future. However, our simulations show that the gains from hedging depend crucially on the initial level of the net debt. A hedging strategy that is welfare improving ex ante may become welfare reducing ex post if a series of adverse and unhedgable shocks occur that cause the net debt to increase significantly in the future. Finding a welfare-enhancing hedging strategy that is also time-consistent is another interesting avenue for further research.

We have used Canadian federal finances to illustrate the importance of exogenous fiscal shocks to the rising public debt problems and to explore the feasibility and desirability of systematic fiscal risk management. However, the conceptual framework and empirical methodology that we have employed here could also be applied to the fiscal problems of other OECD countries, as well as to those of the US states and Canadian provinces. Such analysis is important given the emphasis on governments' responses to fiscal shocks in the current literature on budget deficits.

In analyzing the role of fiscal risk management, we have focused on diversifiable shocks to the government's primary surplus. Since not all the shocks to the primary surplus can be hedged away, there is still a need for the government to smooth cash flows intertemporally by issuing riskfree bonds. Thus, debt management in the form of hedging interest rate risk and choosing the optimal maturity structure as suggested by, among others, Boothe and Reid (1991), Missale and Blanchard (1994) and Barro (1995) are also important for maintaining stability and enhancing the sustainability of fiscal policy. The risk management strategy we emphasize here is complementary to their suggestions on debt management. 


\section{References}

A. B. Abel, “Asset Prices Under Habit Formation and Catching Up With the Joneses," American Economic Review, (1990), 38-42.

A. Alesina and A. Drazen (1991), "Why Are Stabilization Delayed?” American Economic Review, 1, 1170-1188.

A. Alesina and R. Perotti (1995), "The Political Economy of Budget Deficits," IMF Staff Papers, March 1-31.

A. Alesina and R. Perotti (1996), "Budget Deficits and Budget Institutions," NBER working paper no. 5556.

J. Alt and R. Lowry (1994), "Divided Government and Budget Deficits: Evidence for the States," American Political Science Review, forthcoming.

R. J. Barro, (1979), “On the Determination of the Public Debt," Journal of Political Economy, 64, 93-110.

R. J. Barro, (1995), “Optimal Debt Management,” NBER Working Paper no. 5327.

T. Bayoumi and B. Eichengreen (1995), "Restraining Yourself: The Implications of Fiscal Rules for Economic Stabilization," IMF Staff Papers, March, 32-48.

H. Bohn, (1990), “Tax Smoothing with Financial Instruments," American Economic Review, 80, 1217-1230.

H. Bohn, (1991), “The Sustainability of Budget Deficits with Lump-Sum and with Income-Based Taxation," Journal of Money, Credit, and Banking, 23, 580-604.

H. Bohn and R. Inman (1996), "Balanced Budget Rules and Public Deficits: Evidence from the US States,” NBER Working Paper no. 5533.

P. Boothe and B. Reid (1992), "Debt Management Objectives for a Small Open Economy,” Journal of Money, Credit and Banking, 24, 43-60.

J. Y. Campbell, (1996), “Understanding Risk and Return,” Journal of Political Economy, 14 , 298-345.

L. Epstein and S. Zin (1989), "Substitution, Risk Aversion, and Temporal Behavior of Consumption and Asset Returns: A Theoretical Framework,” Econometrica, 5 , 937-969.

Grilli, V., D. Masciandaro, and G. Tabellini (1991), "Political and Monetary Institutions and Public Finance Policies in the Industrial Democracies," Economic Policy, No. 13.

J. M. Harrison and D. M. Kreps, "Martingales and Arbitrage in Multiperiod Securities Markets," Journal of Economic Theory, 2 (1979), 381-408.

IMF, International Finance Statistics, various issues.

N. R. Kocherlakota, “The Equity Premium: It's Still a Puzzle”, Journal of Economic Literature, 34 (1996), 42-71.

Lucas, R. E. and N. L. Stokey (1983), "Optimal Fiscal and Monetary Policy in an Economy 
without Capital," Journal of Monetary Economics, 12, 55-93.

Missale, A. and O. J. Blanchard (1994), "The Debt Burden and Debt Maturity," American Economic Review, 84, 309-319.

Persson, T. and L. Svensson (1989), "Why a Stubborn Conservative Would Run a Deficit: Policy with Time-in-Consistent Preferences," Quarterly Journal of Economics, 104, 325-345.

Poterba, J. (1994), "State Responses to Fiscal Crises: "Natural Experiments" for Studying the Effects of Budgetary Institutions," Journal of Political Economy, June.

Roubini, N. and J. Sachs (1989), "Political and Economic Determinants of Budget Deficits in the Industrial Democracies," European Economic Review, 33, 903-933.

Tabellini, G. (1991), “The Politics of Intergenerational Redistribution," Journal of Political Economy, 99, 335-357.

Tabellini, G. and A. Alesina (1990), "Voting on the Budget Deficit," American Economic Review, 80: 37-49.

Von Hagen, J. (1991), "A Note on the Empirical Effectiveness of Formal Fiscal Restraints," Journal of Public Economics, 44, 99-110.

Von Hagen, J. (1992), "Budgeting Procedures and Fiscal Performance in the European Community," unpublished.

Weil, P. (1989), "The Equity Premium Puzzle and the Risk Free Rate Puzzle," Journal of Monetary Economics, 24, 401-421.

Zhu, X. (1995), "Endogenous Capital Utilization, Investor's Effort, and Optimal Fiscal Policy," Journal of Monetary Economics, 36, 655-677. 
Table 1 ecomposing the Primary Surplus

\begin{tabular}{|c|c|c|c|c|c|c|c|c|}
\hline \hline & Variable & Shock & Lag & Debt & Dummy & Shift & Pre-77 & No Lag \\
\hline \hline & VWR & 0.005 & 0.012 & 0.006 & 0.003 & 0.003 & 0.003 & -0.004 \\
& & $(0.57)$ & $(1.56)$ & $(0.90)$ & $(0.43)$ & $(0.43)$ & $(0.04)$ & $(0.55)$ \\
& DIV & -1.28 & -0.54 & -0.64 & -0.69 & -0.69 & -0.70 & -1.09 \\
& & $(12.97)$ & $(5.01)$ & $(6.06)$ & $(7.04)$ & $(7.09)$ & $(5.05)$ & $(14.18)$ \\
& LONGR & -0.22 & -0.08 & -0.22 & -0.33 & -0.33 & -0.30 & -0.51 \\
& & $(3.57)$ & $(1.59)$ & $(3.73)$ & $(5.62)$ & $(5.68)$ & $(2.53)$ & $(9.24)$ \\
& TBILL & 0.19 & 0.14 & 0.22 & 0.27 & 0.27 & 0.22 & 0.35 \\
& & $(3.34)$ & $(3.29)$ & $(4.88)$ & $(6.26)$ & $(6.34)$ & $(2.47)$ & $(7.71)$ \\
& TBMA & 0.38 & 0.09 & 0.22 & 0.22 & 0.22 & 0.28 & 0.41 \\
& & $(5.92)$ & $(1.46)$ & $(3.13)$ & $(3.82)$ & $(3.97)$ & $(2.47)$ & $(8.46)$ \\
\hline \multirow{5}{*}{ Constant } & 0.0534 & 0.0218 & 0.0167 & 0.0319 & 0.0317 & 0.0319 & 0.0506 \\
& & $(18.70)$ & $(5.48)$ & $(4.21)$ & $(6.64)$ & $(8.39)$ & $(5.35)$ & $(23.15)$ \\
& SLAG & - & 0.61 & 0.50 & 0.38 & 0.38 & 0.24 & - \\
& & & $(9.58)$ & $(7.77)$ & $(5.83)$ & $(5.86)$ & $(2.24)$ & \\
& DEBT & - & - & 0.0070 & -0.0002 & - & - & - \\
& & & & $(4.18)$ & $(0.09)$ & & & \\
& DUM & - & - & - & 0.0109 & 0.0108 & - & 0.0157 \\
& & & & & $(4.91)$ & $(6.70)$ & & $(10.30)$ \\
\hline \hline & NOBS & 148 & 148 & 148 & 148 & 148 & 76 & 148 \\
& $\bar{R}^{2}$ & 0.68 & 0.81 & 0.83 & 0.85 & 0.85 & 0.75 & 0.82 \\
& D-W & 0.69 & 2.06 & 2.06 & 2.03 & 2.04 & 1.96 & 1.20 \\
\hline & CUSUM & 5.69 & 3.63 & 3.21 & - & - & - & - \\
& FTEST & 25.6 & 7.30 & 5.00 & - & - & 2.09 & - \\
& & {$[.000]$} & {$[.000]$} & {$[.000]$} & - & - & {$[0.08]$} & - \\
\hline \hline
\end{tabular}

Notes:

(1) t-statistics are given in parenthesis.

(2) P-values in square brackets.

(3) In the first 3 columns, FTEST refers to a Chow test for a structural break in 1985:2. In sixth column it refers to a test of whether the coefficients on the $\mathrm{X}$-variables in and out of sample are the same.

(4) The X-variables are not demeaned in these regressions. 
Table 2 Implications of edging for Sustainability and elfare

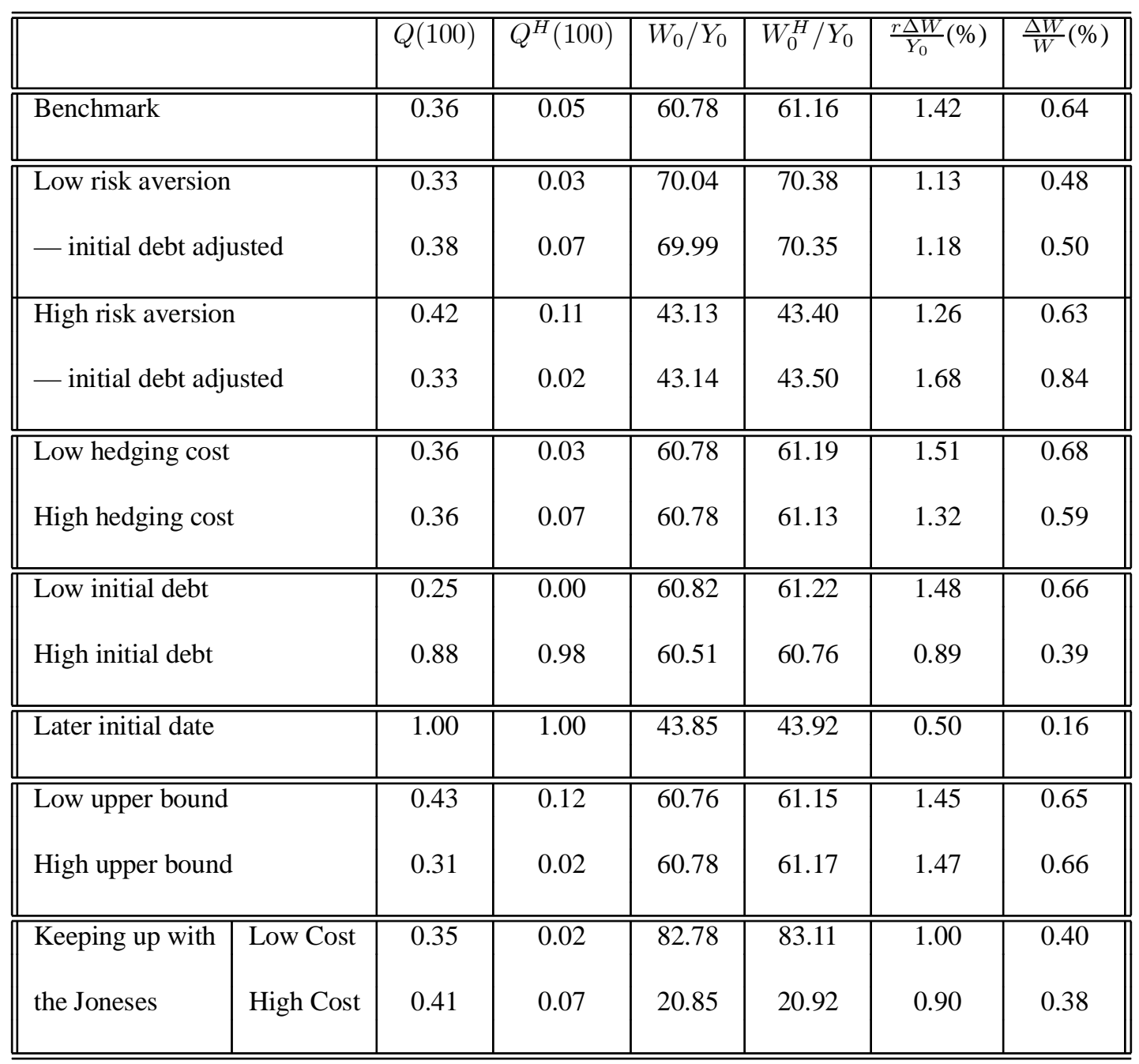

Notes:

(1) Benchmark: $\beta=0.99, \gamma=4, \sigma=0.53331, t_{0}=1977: 1, \phi=0.8$,

(2) Low risk aversion: $\gamma=2, \sigma=0.71578$. High risk aversion: $\gamma=10, \sigma=0.35116$

(3) Low initial net debt: $D-V=0$. High initial net debt: $D-V=0.799$.

(4) Low upper bound: $\phi=0.6$. High upper bound: $\phi=1.00$.

(5) Keeping up with the Joneses. Low cost: $\delta-\gamma=2$. High Cost: $\delta-\gamma=20$. 


\section{Appendix}

\subsection{Data}

All of the data and the programs used in this paper can be downloaded from the internet at http://www.chass.utor

\section{Fiscal ariables}

The quarterly primary surplus was calculated as the difference between total federal revenues and expenditures less interest payments on the debt, as published by Statistics Canada. For institutional reasons, this data exhibits considerable seasonal variation. Specifically, annual crown corporation cash flows are attributed only to the second quarter yielding a large "spike". We therefore used seasonally adjusted data. The surplus data does not include charges and subsidies relating to the Petroleum Compensation fund. Quarterly public debt figures are taken from IMF International Financial Statistics. The effective interest rate was calculated as the ratio of actual interest payments on the debt to value of the debt.

\section{Asset Returns}

VWR is the index of value-weighted returns on the NYSE taken from the CRSP tape. DIV is the dividend yield on the NYSE from the CRSP tape. LONGR is the nominal interest rate on 10 year US. government bonds. TBILL is the nominal 3-month US. treasury bill rate. TBMA is a one-year fixed-weight moving average of TBILL. All of these returns were converted into Canadian dollars using the spot U.S.-Canadian exchange rate taken from CITIBASE. Note that these returns should therefore be interpreted as the return in Canadian dollars on each U.S. dollar invested.

\section{3 ata used to Compute the Stochastic iscount Factor}

Real per capita US consumption was calculated using data from CITIBASE. The real rate of return on the market portfolio was taken to be equal to VWR divided by the US CPI.

\subsection{Details of Algorithm}

\section{Asset aluation}

At time $t=0$, we use the VAR process to forecast the present value of each component of the primary surplus. The time $t$ Canadian dollar prices for a vector of assets with nominal return stream $\left\{\mathbf{X}_{\tau}\right\}_{\tau>t}$ is

$$
\pi_{t}=\frac{1}{M_{t}} \sum_{\tau=t}^{\infty} E_{t}\left[M_{\tau} X_{\tau}\right]
$$


We compute these prices as follows. Let $\mathbf{m}_{x}(t, \tau)$ and $m_{z}(t, \tau)$ denote the $\tau$-period ahead expected value of the financial return vector and the $\log$ of the stochastic discount factor, respectively. Let $\mathbf{V}_{\mathbf{x x}}(\tau), \mathbf{V}_{\mathbf{x z}}(\tau)$ and $V_{z z}(\tau)$ denote the blocks of the $\tau$-period ahead covariance matrix from the VAR. The distributional assumptions made in Section 3 imply that the present value of the vector of returns at time $\tau, \mathbf{X}_{\tau}$, given information available at time $t$ is

$$
\begin{aligned}
E_{t}\left[M_{\tau} \mathbf{X}_{\tau}\right] & =\bar{y}_{t} \exp [(\xi+b) \tau] \beta^{\theta \tau} E_{t}\left[\exp \left(Z_{\tau}\right) \mathbf{X}_{\tau}\right] \\
& =\bar{y}_{t} \exp [(\xi+b) \tau] \beta^{\theta \tau} \exp \left(m_{z}(t, \tau)+\frac{1}{2} V_{z z}(\tau)\right)\left[\mathbf{m}_{x}(t, \tau)+\mathbf{V}_{x z}(\tau)\right]
\end{aligned}
$$

Here the relevant means and covariances can be computed recursively as follows:

$$
\begin{aligned}
& \mathbf{m}_{x}(t, \tau)=E_{t}\left[\mathbf{X}_{\tau}\right]=\mathbf{A m}_{\mathbf{x}}(t, \tau-1) \\
& m_{z}(t, \tau)=\mathbf{c}^{\prime} \mathbf{m}_{\mathbf{x}}(t, \tau-1)+m_{z}(t, \tau-1) \\
& \mathbf{V}_{\mathbf{x z}}(\tau)=\mathbf{A V}_{\mathbf{x x}}(\tau-1) \mathbf{c}+\mathbf{A V}_{\mathbf{x z}}(\tau-1)+\mathbf{v} \\
& V_{z z}(\tau)=\mathbf{c}^{\prime} \mathbf{V}_{\mathbf{x x}}(\tau-1) \mathbf{c}+V_{z z}(\tau-1)+\mathbf{c}^{\prime} \mathbf{V}_{\mathbf{x z}}(\tau-1)+\sigma_{\eta}^{2} \\
& \mathbf{V}_{\mathbf{x x}}(\tau)=\mathbf{A V}_{\mathbf{x x}}(\tau-1) \mathbf{A}^{\prime}+\mathbf{\Sigma}
\end{aligned}
$$

where the parameters of (A4) are obtained from the restricted VAR. Initial values are $\mathbf{m}_{\mathbf{x}}(t, 1)=$ $\mathbf{A X}_{t}, m_{z}(t, 1)=\mathbf{c}^{\prime} \mathbf{X}_{t}+Z_{t}, \mathbf{V}_{\mathbf{x z}}(1)=\mathbf{v}, V_{z z}(1)=\sigma_{\eta}^{2}$ and $\mathbf{V}_{\mathbf{x x}}(1)=\mathbf{\Sigma}$.

The above can be used to construct the present value of the return stream TBMA, the one-year moving average of TBILL. Let $m_{4}(t, \tau)$ denote the $\tau$-period ahead expected value of TBILL, and let $\mathbf{V}_{4 x}(\tau)$ and $V_{4 z}(\tau)$ denote the covariance vector between TBILL and $\mathbf{X}_{\mathbf{t}}$, and the covariance between TBILL and $Z_{t}$, respectively. Then, the $\tau$-period ahead expected value of TBMA is given by

$$
m_{5}(t, \tau)=\frac{1}{4}\left[m_{4}(t, \tau-1)+m_{4}(t, \tau-2)+m_{4}(t, \tau-3)+m_{4}(t, \tau-4)\right]
$$

The conditional covariance vector of TBMA with $X_{t}$ is

$$
\mathbf{V}_{\mathbf{x} \mathbf{5}}=\frac{1}{4}\left[\mathbf{A V}_{\mathbf{4 x}}(\tau-1)+\mathbf{A}^{2} V_{4 x}(\tau-2)+\mathbf{A}^{\mathbf{3}} \mathbf{V}_{\mathbf{4 x}}(\tau-3)+\mathbf{A}^{\mathbf{4}} \mathbf{V}_{\mathbf{4 x}}(\tau-4)\right]
$$

and the conditional covariance with $Z_{t}$ is

$$
\begin{aligned}
V_{5 z}= & \frac{1}{4}\left[V_{4 z}(\tau-1)+V_{4 z}(\tau-2)+V_{4 z}(\tau-3)+V_{4 z}(\tau-4)\right]+ \\
& \frac{1}{4} \mathbf{c}^{\prime}\left[\mathbf{V}_{\mathbf{4 x}}(\tau-4) \mathbf{V}_{\mathbf{4 x}}(\tau-1)(\mathbf{I}+\mathbf{A}) \mathbf{V}_{\mathbf{4 x}}(\tau-2)+\left(\mathbf{I}+\mathbf{A}+\mathbf{A}^{\mathbf{2}}\right) \mathbf{V}_{4 \mathbf{x}}(\tau-3)\right]+ \\
& \frac{1}{4} \mathbf{c}^{\prime}\left(\mathbf{I}+\mathbf{A}+\mathbf{A}^{\mathbf{2}}+\mathbf{A}^{\mathbf{3}}\right) \mathbf{V}_{\mathbf{4 x}}(\tau-4)
\end{aligned}
$$

Eventually, after $T$ periods the growth in the mean and variance of $M_{t}$ converge to constants $\Delta m_{Z}^{*}$ and $\Delta V_{Z Z}^{*}$ respectively.. It follows that we can write

$$
\mathrm{E}_{t}\left[M_{T+\tau} X_{T+\tau}\right]=\exp \left[\left(\rho+\Delta m_{Z}^{*}+\frac{1}{2} \Delta V_{Z Z}^{*}\right) \tau\right] \mathrm{E}_{t}\left[M_{T} X_{T}\right]
$$

$\rho=\theta \ln \beta+\xi+b<0$. We can therefore evaluate the present value of the cash flow $X_{t}$ by iteration using (A5), (A6) and (A7) for the first $T$ periods, then adding the appropriate long run constant 
term:

$$
\pi_{t}=\frac{1}{M_{t}} \sum_{\tau=t}^{T} \mathrm{E}_{t}\left[M_{\tau} \mathbf{X}_{\tau}\right]+\frac{\bar{y}_{t} \exp [\rho T]}{1-\bar{y}_{t} \exp \left[\rho T+\Delta m_{Z}^{*}+\frac{1}{2} \Delta V_{Z Z}^{*}\right]} \mathrm{E}_{t}\left[M_{T} X_{T}\right]
$$

Note that to calibrate the model, for each value of $\gamma$ we choose a value of $\sigma$ (fixing $\beta=0.99$ ) that ensures that the long run theoretical risk-free quarterly interest rate,

$$
R^{*}=-\frac{1-\gamma}{1-\frac{1}{\sigma}} \ln (\beta)+b+\Delta m_{Z}^{*}+\Delta V_{Z Z}^{*}
$$

is fixed at 0.03 .

\section{Computation of Fiscal Policy Sustainability and elfare}

To compute the probability of policy shifts and the associated welfare impacts, we conducted a Monte Carlo simulation. For each set of parameters, we estimated the underlying VAR to determine the parameters of the system and the associated joint distribution of the errors. We used this to generate random draws for $\varepsilon_{t}, \eta_{t}$ and $\mathbf{u}_{t}$ with the required joint distribution and generated $N$ paths of $T$ periods for the entire system. ${ }^{24}$ For each path and at each date, we computed the implied debt level, $D_{t}$, and the present value of future forecasted primary surpluses under the current policy, $V_{t}\left(\theta_{t}\right)$. We did this for both the hedged and unhedged government cash flow processes. We then computed the associated net debt and used it to determine the tax rate to be set in the next period according to the policy rule described in (17). This generated a numerical distribution over the tax rate which we used to compute welfare. ${ }^{25}$ Since changes in the tax rate occur infrequently (i.e. only when the bounds on the net debt are hit), a large number of paths and time periods were required before our estimated welfare gain converged. Specifically, $N=150,000$ and $T=600$ were sufficient for convergence of the welfare gain estimate up to the third decimal place.

24 Since the relevant distributions are symmetric around zero, we accelerated the convergence by using the draw itself and its negative.

25 Note of course that the debt and present value calculation is endogenous to the policy choice. 